\title{
Sewage disposal and arboviruses in Brazil
}

Luciano Pamplona de Góes Cavalcanti ${ }^{1}$, Artur Timerman ${ }^{2}$

It is known that the actions intended to expand the sewage disposal coverage and the access to drinking water have an impact on people's health. Nevertheless, what is the possible association between these actions and the decrease in vector-borne diseases?

In Brazil, sewage disposal has advanced significantly in the last few years, but it is not enough. One of the Millennium Development Goals, with respect to ensuring environmental sustainability, was to reduce the proportion of people without sustainable access to water and sewer. Part of this goal was achieved by Brazil, when it expanded the percentage of the population with public network water supply from $70.0 \%$, in 1990 , to $85.5 \%$, in 2012. However, this percentage is not homogeneous and there is a considerable discrepancy among the different regions of the country.

There is a great worldwide effort to promote improvements in the living conditions of people and access to sewage disposal. A recent example of this effort is the 2030 Agenda for sustainable development. Among the several proposed goals, one is aimed to achieve universal access to drinking water by the year 2030. In Brazil, the National Plan for Sewage Disposal has short, medium and long-term goals concerning the universalization of sewage disposal services ${ }^{1}$. The critical issue is the estimated time to reach the universal access of these basic and fundamental rights. To make matters worse, we are faced with epidemics associated with arboviruses directly linked to these conditions, which require urgent responses.

Even in large urban centers located in the South and Southeast of Brazil, since 2015, people face a severe hydrological crisis. Concomitantly, they also face a sanitary crisis caused by mosquito-borne diseases (Aedes aegypti and albopictus), such as Dengue, Chikungunya and Zika. There is evidence to suggest that the dispersion and/or maintenance of these diseases is tightly related to the precariousness of sewage disposal and water supply.

The Aedes aegypti is an urban and domestic mosquito that has habits absolutely related to human conditions. In some Brazilian regions, the main breeding places are small natural reservoirs; in others, tanks used for water storage for human consumption. This variation occurs among the different regions of the country and also in the different neighborhoods of a same town. In the Brazilian Northeast, in general, the main infested reservoirs are the great tanks used to store water, and the existence of these reservoirs is directly linked to the absence or intermittency in the supply of drinking water.

Accordingly, the act of thinking about a sustainable control for these epidemics inevitably involves, among other factors, the need for a system capable of providing water in sufficient quantity and in the place desired by the people. In addition, it requires a sewage network capable of capturing and treating the amount that was consumed. It is obvious that sewage disposal alone is not able to solve the issue of these arboviruses, but it is an initial and giant step in order to solve definitively this situation that affects the Brazilian population.

\section{References}

1. Ministério das Cidades (BR). Plano Nacional de Saneamento Básico [Internet]. 2013 [citado 2016 ago 31]. Disponível em: www.cidades.gov.br/images/stories/ArquivosSNSA/Arquivos_PDF/plansab_06-12-2013

\footnotetext{
${ }^{1}$ Universidade Federal do Ceará. Fortaleza, CE, Brazil.

${ }^{2}$ Sociedade Brasileira de Dengue/Arboviroses. São Paulo, SP, Brazil.

Corresponding author: Luciano Pamplona de Góes Cavalcanti

Rua Professor Costa Mendes, 1608 - Rodolfo Teófilo, CEP: 60430-140. Fortaleza, CE, Brazil. E-mail: pamplona.luciano@gmail.com
} 